\title{
Recommendations for Ramadan fasting to patients with cardiovascular diseases; Turkish Society of Cardiology consensus report
}

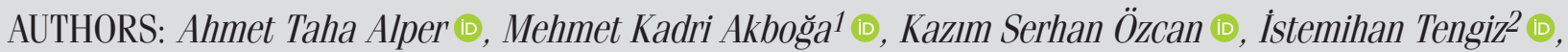 \\ Uğur Önsel Türk², Mustafa Yıldız³ (iD, Mehmet Birhan Yılmaz ${ }^{4}$ (D)

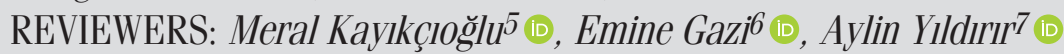 \\ Department of Cardiology, University of Health and Sciences, Siyami Ersek Training and Research Hospital; İstanbul-Turkey \\ 1Department of Cardiology, Faculty of Medicine, Gazi University; Ankara-Turkey \\ ${ }^{2}$ Department of Cardiology, Medical Park İzmir Hospital; İzmir-Turkey \\ ${ }^{3}$ Department of Cardiology, Institute of Cardiology, İstanbul University-Cerrahpaşa; İstanbul-Turkey \\ ${ }^{4}$ Department of Cardiology, Faculty of Medicine, Dokuz Eylül University; İmir-Turkey \\ ${ }^{5}$ Department of Cardiology, Faculty of Medicine, Ege University; İmir-Turkey \\ ${ }^{6}$ Department of Cardiology, Faculty of Medicine, Çanakkale Onsekiz Mart University; Çanakkale-Turkey \\ ${ }^{7}$ Department of Cardiology, Faculty of Medicine, Başkent University; Ankara-Turkey
}

Cite this article as: Alper AT, Akboğa MK, Özcan KS, Tengiz I, Türk UÖ, YIldız M, et al. Recommendations for Ramadan fasting to patients with cardiovascular diseases; Turkish Society of Cardiology consensus report. Anatol J Cardiol 2021; 25: 284-93.

\section{Introduction}

Fasting is one of the important rituals in Islam. According to the Islamic faith, it is an obligation for all Muslims. It is also a common practice in other religions such as Christianity, Judaism, and Hinduism and for philosophies such as Buddhism, Taoism, and Jainism. Each belief or sect has a different type of fasting according to their creed. The fasting period and practice may differ. For example, the Ramadan for Sunni Muslims, Muharram for Alevi Muslims and Lent for Catholics are specific periods for fasting. Ramadan fasting lasts for 29-30 days, Muharram fasting for 10-12 days, and Lent fasting lasts for 40 days. The Ramadan fasting period may vary with the geographic region, but generally it is 12 hours long. It can be as long as 22 hours in the polar regions during summertime (1-4).

The practice of fasting in Islam is a mandatory ritual for every healthy individuals, but fasting is be optional for those who are too sick to fast. But what sickness permits breaking the fast is not clear. Therefore, the eligibility or the lack of it to fast is steeped in controversy for some sick people. Particularly in the last 2 decades, numerous studies have been published regarding the effects of religious fasting on general health. More than 1000 articles are available on the PubMed database related to
Ramadan and Lent/Biblical fasting. However, there is limited evidence for this topic, and most studies are retrospective with a limited number of patients. Moreover, in general, the quality is poor with limited conclusions to draw suggestions for clinical practice $(5,6)$. Furthermore, it is impossible to conduct randomized controlled trials on religious fasting to reach more conclusive results.

The main objective of the current paper is to summarize the current literature on Ramadan fasting and discuss the potential beneficial or adverse effects on patients with or at risk of cardiovascular disease. The second aim is to propose an evidencebased suggestion regarding who is eligible and not eligible for fasting. Specific highlights and consideration for each patient group are discussed in following sections and summarized in Table 1.

The effect of Ramadan fasting on health and cardiovascular risk factors

In general, the main aim of most fasts is to stop eating and drinking for a period of time. This activity change may also affect exercise, sleep, and smoking habits in this specific duration. Therefore, it is clear that lifestyle changes could have a significant impact on the cardiovascular system (1-4).

Address for Correspondence: Dr. Ahmet Taha Alper, Siyami Ersek Göğüs Kalp ve

Damar Cerrahisi Eğitim ve Araştırma Hastanesi, Tıbbiye Caddesi, Üsküdar, 34668, İstanbul-Türkiye

Phone: +90 2164445257 E-mail: draalper@gmail.com

Accepted Date: 01.04.2021 Available Online Date: 17.04.2021

(C) Copyright 2021 by Turkish Society of Cardiology - Available online at www.anatoljcardiol.com

DOI:10.5152/AnatolJCardiol.2021.206 
Table 1. Consensus statements on Ramadan fasting in patients with cardiovascular diseases

Consensus statements

Cardiovascular prevention and cardiovascular diseases

Recommendation

References

All patients with type $2 \mathrm{DM}$ willing to fast should be warned of strict adherence to

$8,18,21,29$

medications and healthy diet during fasting

All patients with CAD willing to fast should be evaluated on an individual basis by physicians, and potential risks must be discussed.

Fasting may be tolerated in most patients with stable chronic coronary syndrome.

Fasting should be avoided in patients with CKD accompanied with CAD owing to increased risk of kidney injury and thrombosis.

Fasting should be avoided in patients with recent $\mathrm{PCI}$ (within three months), because of dehydration associated risk of stent thrombosis.

Fasting should be avoided in patients with recent acute coronary syndrome (within three months).

\section{Patients with heart failure (HF)}

All patients with HF willing to fast should be warned of strict adherence to prognostically important medications and proper diet during fasting as it can worsen the prognosis.

All patients with HF willing to fast should be evaluated for their medications, including tolerability to patient-centered down-titration of diuretics during fasting.

All patients with HF willing to fast should undergo individualized medical examination for potential alterations of prognostically important medications.

All patients with HF should be evaluated for comorbidities which can potentially alter the prognosis related to fasting state in HF.

Fasting may be tolerated in most patients with HF with NYHA Class I-II-III symptoms with no recent decompensation given the prescribed frequencies of medications can be tolerated.

Fasting should be avoided in patients with HF with NYHA Class IV symptoms.

Patients with HF requiring administration of medications during the time window of fasting, which should be individualized according to season, should be advised against fasting.

During Ramadan fasting, excess licorice consumption may create a state of hypernatremia, hypokalemia, and increased fluid volume, which can cause serious life-threatening complications; therefore, should be avoided in patients with HF.

\section{Patients with hypertension (HT)}

All patients with HT willing to fast should be evaluated on an individual basis by physicians, and potential risks must be discussed.

All patients with HT willing to fast should be warned about strict adherence medications and healthy diet during fasting.

Fasting may be tolerated in patients with controlled HT.

If possible, thrice daily medications may be switched to twice daily (before fasting starts and after breaking fast in the evening).

If possible, single pill strategy (once-daily medication) with long-acting preparations may be preferred.

Fasting should be avoided in patients with uncontrolled HT.

Diuretics are not recommended during fasting, especially in hot climates.

P

\section{Patients with arrhythmias}

All patients with atrial arrhythmias willing to fast should be evaluated on an individual basis by physicians, and potential risks must be discussed. 
All patients with ventricular arrhythmias willing to fast should be evaluated on an individual basis by physicians, and potential risks must be discussed.

$35,45,49,54$

24,47

Fasting may be tolerated in the majority of patients with atrial fibrillation and

$48^{*}$

All patients with intracardiac devices may be evaluated on an individual basis, and fasting may be allowed depending on their heart failure or arrhythmia status.

Fasting should be avoided in patients with HOCM owing to the risk of dehydration.

$48,55^{*}$

Fasting should be avoided in patients with Brugada syndrome.

$49,50,51,52$

Fasting should be avoided in patients with long-OT syndrome.

Fasting should be avoided in patients with uncontrolled ventricular arrhythmias.

$35,45,49,54$

\section{Recommendations for exercise during Ramadan fasting}

Exercise is recommended after sunset and before sunrise to prevent the occurrence of progressive dehydration because of sweat losses, insufficient fluid and electrolyte consumption

Competitive physical activities such as football and volleyball should be organized after sunset.

Training loads, food and fluid intake, and sleep habits of the athletes should be monitored carefully if the athletes are training or competing during Ramadan fasting.

Performing intense training sessions in the early evening or the late afternoon may be considered.

\section{Other cardiovascular disorders}

All patients with valvular heart disease willing to fast should be evaluated on an individual basis by physicians, and potential risks must be discussed.

All patients with pulmonary hypertension willing to fast should be evaluated on an individual basis by physicians, and potential risks must be discussed.

Fasting may be tolerated in patients with mild to moderate valvular heart disease.

Fasting may be tolerated in patients with mild to moderate pulmonary hypertension.

Fasting should be avoided in patients with severe valvular heart disease.

Fasting should be avoided in patients with severe pulmonary hypertension.

\section{Cardiovascular drug therapy during Ramadan fasting}

Patients should seek medical advice before Ramadan and be advised to discuss their drug therapy and dosage regimen adjustments with their physician.

Patients with higher risk of adverse drug reactions (elderly who have impaired kidney functions, poly pharmacy, and multiple comorbidities, etc.) should be monitored closely.

If possible, thrice daily medications may be switched to twice daily or once daily regimens if there are equivalent alternatives.

If possible, once daily regimens may be preferred.
$56,57,58,59$ 60,61

$56,57,58,59$ 60,61

$56,57,58,59$, 60,61

$56,57,58,59$ 60,61

$48^{*}$

$48^{*}$

$48 *$

$48^{*}$

$48 *$

$48^{*}$

$62,63,64$

$62,63,64$

$39,62,63,64$

$39,62,63,64$

Green heart refers to "is indicated, is recommended," yellow heart refers to "may be indicated, may be recommended," red heart refers to "contraindicated, not recommended, should be avoided."

*These patient groups are less studied in the literature. Therefore, the recommendations are determined as expert opinion.

** Specific recommendations about individual drugs are mentioned in the text.

CAD - coronary artery disease, CKD - chronic kidney disease, DM - diabetes mellitus, HF - heart failure, HOCM - hypertrophic obstructive cardiomyopathy, PCI - percutaneous coronary intervention 
Ramadan fasting has unique properties common with intermittent fasting, which is currently a popular eating pattern used for losing weight with alternating cycles of fasting and eating periods. During Ramadan fasting, food and fluid intake is forbidden daily from dawn to sunset for a month. Different from other fasting regimens like caloric restriction, Ramadan fasting is timerestricted, intermittent, and circadian. Ramadan fasting is a form of intermittent fasting where the eating pattern shifts to a nocturnal eating pattern, but the major limitation of Ramadan fasting involves the complete restriction of fluid intake including water during the fasting period. Intermittent fasting has positive effects on insulin resistance and cardiovascular risk markers $(7,8)$.

Ramadan fasting has also positive effects on decreasing psychological stress, depression, and anxiety (9-11). In addition, Ramadan fasting, which is a religious duty, is associated with decreased heart rate, respiratory rate, and blood pressure (BP) (12).

Since 17.9 million people die every year due to cardiovascular diseases (CVD), the effects of the fasting on CVD continue to be the subject of many studies $(13,14)$. Inflammation and oxidative stress are increasingly emphasized today as contributors to a range of disease states, and a kind of predictor of cardiovascular risk is being considered. Ramadan fasting reduces the concentration of pro-inflammatory factors contributing atherosclerosis, such as homocysteine, interleukin-6 (IL-6), or C-reactive protein (CRP) (15). Both systolic and diastolic BP reduce during the fasting $(16,17)$. This is explained by a decrease in sympathetic tone counterbalanced by an increase in parasympathetic tone. Higher vagal activity has been associated with decreased levels of inflammatory cytokines (18). Therefore, the fasting appears to be effective in lowering BP and may reduce CVD mortality (19). The fasting also appears to have a positive effect on blood lipids such as HDL, LDL, triglycerides, and very low-density lipoprotein levels, resulting in a decrease in the average Framingham risk score of 13.8 to 10.8 (17).

The relationship between intermittent fasting and diabetes is complicated. The data do not consistently support improvements in fasting glucose levels, which may be due to a latency period or missed glucose fluctuations during the day (18). Therefore, patients with type 2 diabetes mellitus require close monitoring during Ramadan fasting. Carbohydrate intake should be discouraged, and physical activity should be encouraged to improve insulin sensitivity and associated glucose metabolism (19). Depending on the geographic location, the climate and seasonal timing of Ramadan fasting may differ. Especially, geographic locations with warmer climates and long fasting hours increase the risk of hypoglycemia and dehydration in fasting people. Moreover, after long periods of fasting excessive caloric intake can worsen the clinical status of patients. Therefore, patients should be warned to ensure strict adherence to a healthy dietary pattern during Ramadan. Fasting of patients with chronic kidney disease (CKD) may lead to dehydration and hyperviscosity, predisposing them to further kidney injury and thrombosis of the calcified blood vessels. Pre-existing CVD and early increase in serum creatinine levels are the main risk factors (20). In a meta-analysis of two studies covering 648 patients, fasting individuals had a lower risk of coronary artery disease with an odds ratio of 0.65 (Cl $0.46-0.94)$ (21). Temizhan et al. (22) reported a significantly lower incidence of hospitalization for acute coronary syndromes during the fasting month of Ramadan in Turkey while Burazeri et al. (23) reported a $72 \%$ reduction in the risk of acute coronary syndrome in Muslims who fasted regularly during Ramadan in Albania.

The effect of Ramadan fasting after a cardiovascular event

The fasting may provide cardiac protection even after a cardiovascular event. Several studies have observed that Muslims with a history of ischemic cardiomyopathy had a decreased incidence of acute decompensated heart failure during Ramadan compared to the rest of the year $(19,24)$.

Most patients with stable heart disease can fast without any significant complications. Patients taking medications thrice daily may be switched to twice daily or once daily regimens (25). Fasting within the first 3 months can be dangerous in newly revascularized patients following an acute coronary syndrome (26). Thrombosis risk is higher in patients with high SYNTAX (score $>22$ ) or after a complex $\mathrm{PCl}$ procedure (26). The main factor is thought to be dehydration and, therefore, a tendency to stent thrombosis especially in the summertime fasting (26). After 3 months, fasting may become safe in those patients. Although there is no definite consensus, it seems safer for stable patients who are followed up with proper medical treatment after an acute coronary syndrome to fast after completing the first 3 months following the index event. Changing the schedule of long-acting dual antiplatelet therapy for fasting does not cause any significant adverse event after that period (26). However, individual evaluation of patients with coronary artery disease is essential. This period can be extended based on the individual risk assessment, especially in high-risk patients.

During Ramadan fasting, excess licorice consumption may cause hypernatremia, hypokalemia, and increased fluid volume, which may trigger severe life-threatening complications such as hypertensive pulmonary edema in patients with CVD (27). It is also important to educate and follow up patients on drugs with a narrow therapeutic window such as warfarin and digoxin during fasting because, with the changing diet and dehydration, serum concentration of these drugs could be affected, leading to increased bleeding or intoxication risk $(28,29)$. Therefore, patients should be warned before the fasting month, not to change the dietary components during the eating periods between the fasting periods.

\section{Ramadan fasting with heart failure}

During the intermittent fasting periods, ketosis could develop due to several hours of abstinence from food. In relation to this ketotic state, several observations and scientific studies have been undertaken. The most interesting one is related to the heart failure (HF) status. Ketotic bodies are a better source of fuel for a failing heart simply by facilitating oxidation of the mitochondrial coenzyme $\mathrm{Q}$ coupling and improving the free energy of cytosolic ATP hydrolysis (30). Energetically, mitochondria of the 
failing myocardium seeks the ketogenic state created by fasting or SGLT-2 inhibitors which have recently been shown to improve prognosis (31). In relation to the reduced capacity to oxidize fatty acids, ketone body oxidation becomes the main fuel source for both HFrEF and HFpEF (32). Besides, it has recently been shown that ketone bodies at low levels, as observed during the fasting state, may exert beneficial effects on endothelial cells by modulating the inflammatory status, though the high levels observed during diabetic ketoacidosis might yield detrimental consequences (33). Hence, hypothetically, a mildly ketotic environment created by fasting seems to provide an advantage in patients with HF.

Literature regarding the outcome of patients with $\mathrm{HF}$ and fasting is limited. However, Salam et al. (24) have shown, according to the registry data from the Middle East, that patients admitted with acute HF during Ramadan had significantly lower prevalence of symptoms and signs of systemic congestion compared with patients hospitalized in other months. Furthermore, acute HF hospitalization in Ramadan was not linked to worse prognosis in several analyses (24). This analysis was confirmatory to a previous one which investigated a 10-year trend in hospitalizations for acute HF and showed that there was no difference in the number of acute HF hospitalizations during fasting in Ramadan compared to the non-fasting months (34). It seems the fasting state resulted in a dried and hence decongested state secondary to abstaining from water and salt ingestion as reported by Hassan et al. (35) who has shown a reduction in plasma brain natriuretic peptide levels in patients with mild to moderate chronic kidney disease, though, the glomerular filtration rate remained unchanged. Another study by Abazid et al. (36) investigated the influence of Ramadan fasting on outcomes of chronic HF outpatients. They showed that during Ramadan fasting, $8 \%$ of HF patients developed instability, and those patients were significantly less adherent to either medications or diets compared to those who remained stable during Ramadan along with a similar distribution of the NYHA functional class before Ramadan period. Recently, Nielsen et al. (37) showed that intravenous administration of hydroxybutyrate, which resulted in significant increase in cardiac output, stroke volume, and ejection fraction among chronic HFrEF patients, indirectly verified the scientific observation that a mild ketotic state like fasting would be advantageous to the failing heart.

In conclusion, given the fasting-generated positive impact of the ketotic state, overall fasting seems beneficial for failing cardiomyocytes along with safety signals derived from the registry data. However, there is a risk of abandoning medications and diet, which can potentially deteriorate the prognosis. Hence, adjustment of medications prior to planned fasting by pre-fasting scheduled visits might help adapt to and overcome potentially hazardous complications. Of note, achieving once-daily medication either before or at the end of fasting might not be possible for some patients. Hence, an individualized approach should be undertaken whenever possible and solutions discussed mutually.

\section{Ramadan fasting and hypertension}

Many factors may theoretically influence BP during Ramadan fasting. These include feeding patterns, sleep changes, type of antihypertensive agents, and changes in the timing of medication intake. People may wake up before sunrise for the first meal, return to sleep, fast for the rest of the day, and some add an afternoon nap during this month. These behavioral changes might cause alterations in BP level.

People with mild hypertension can safely undertake Ramadan fasting with once-only daily preparation (38). It has been reported that ambulatory BP in treated hypertensive patients did not differ before and during Ramadan in fasting individuals (39). This has been also confirmed that in patients with controlled grade 2-3 hypertension - 24-hour ambulatory BP recordings do not change during Ramadan fasting (40). Taking antihypertensive medications twice daily (before fasting starts at dawn, and just after breaking the fast in the evening) seems to be the correct regimen for BP control. A recent study assessed BP changes during Ramadan fasting in prehypertensive and hypertensive patients who did not use antihypertensive agents (41). The study revealed that during Ramadan, there was a significant reduction in $\mathrm{BP}$, including during the 24-h ambulatory BP monitoring. These studies conclude that Ramadan fasting could be well-tolerated in patients with uncomplicated essential hypertension (42). The variations in BP are minimal and are probably related to the changes in activity, sleep, and also feeding patterns. However, these studies have certain limitations (41, 42). They were carried out when Ramadan fell in winter when the fasting duration was around 12 hours. However, if Ramadan falls in summer, the required period for fasting can last up to 18 hours. Therefore, the pharmacokinetic and pharmacodynamic effects of longer fasting periods are unknown, especially in hot climates.

An increased number of hypertension-related visits to emergency departments in Ramadan has been reported (43). Poor compliance with the treatment regimens by fasting patients or other neuroendocrine changes induced by unaccustomed hunger periods might have contributed to this finding. Fasting patients with hypertensive emergencies should be treated appropriately, including by intravenous medications.

\section{Patients with arrhythmias}

There is little evidence on the effects of fasting in patients with arrhythmias in the current literature. Two studies have evaluated the effects of Ramadan fasting on heart rate variability which is an important predictor of arrhythmias and reported that fasting affects both heart rate variability and the balance between the parasympathetic and sympathetic system $(44,45)$. In experimental animal studies, it has been reported that hypoglycemia can induce fatal cardiac arrhythmias (46). During the evaluation of these patients, clinicians should be aware of the potential role of fasting in triggering arrhythmias.

Salam et al. (47) have evaluated the effects of Ramadan fasting on atrial fibrillation burden and hospitalization. They showed a neutral effect of the fasting on atrial fibrillation, and the inci- 
dence was not different when compared a month before Ramadan fasting. In another study from the same authors, the incidence of atrial arrhythmias was not increased in patients with HF during Ramadan fasting (24). However, sleep cycle disturbance observed during the fasting and eating periods can increase the incidence of atrial fibrillation $(25,48)$. Moreover, fasting significantly increases mean INR values in patients receiving warfarin therapy, whereas INR values decreases after Ramadan fasting (28). Based on the abovementioned data, fasting may be well-tolerated in most of patients with supraventricular arrhythmias and atrial fibrillation (48). Anticoagulant drugs, especially warfarin, can be managed in accordance with clinical follow up (48). Here, the pre-fasting visit for education of the patient on how to receive medications and what precautions should be covered is extremely important to ensure adverse outcomes do not increase during the fasting month of Ramadan.

It has been shown that glucose-induced insulin secretion unmasks ST segment elevation in patients with Brugada syndrome (49-51). Morphological changes and augmentation of ST elevations occur more frequently after post-prandial periods, especially following dinner (49-51). However, ECG abnormalities can be unmasked after full stomach tests with large meals (51). After a long fasting period, a heavy dinner can cause fatal arrhythmias in patients with the Brugada syndrome (52). Patients with Long-OT syndrome type 2 have been reported to have abnormal pancreatic functions, including increased incretin and insulin secretions which lead to low plasma glucose levels (53). Hypoglycemia could easily cause OT prolongation leading to malignant arrhythmias in these patients (53). Therefore, patients with Brugada syndrome and Long-OT syndrome type 2 are advised not to fast during Ramadan $(47,53)$. Kahraman et al. (54) reported that the frequency of idiopathic premature ventricular complex is increased during the fasting and decreased after intermittent fasting. Patients with ventricular arrhythmias should be evaluated on an individual basis for fasting as there are no randomized clinical trials in the current literature. Patients with uncontrolled ventricular arrhythmias should also avoid fasting during Ramadan (47).

It is recommended that patients with hypertrophic obstructive cardiomyopathy (HOCM) avoid dehydration which may precipitate symptoms of dyspnea and syncope (55). Based on this recommendation, patients with HOCM should avoid fasting, which can induce these symptoms (47).

Patients with intracardiac devices should be evaluated on an individual basis with regard to the underlying cardiac disease and its current status (47). Electrolyte abnormalities during long fasting periods in patients on-treatment with diuretics may alter pacemaker functions (47).There is very limited data on the other forms of cardiac arrhythmias in the current literature.

\section{Fasting and sports}

With the time-restricted, intermittent, and circadian nature of Ramadan fasting, athletes and non-athletic people are prone to develop dehydration and sleep disturbances. There is a growing consensus that through increasing lipolysis in muscles and adipose tissue, physical training and fasting have beneficial effects on body composition and health (56-61). It is especially important for athletes, as they need to control their body composition to optimize the balance between lean and body fat mass to improve their performances (55-58). To prevent hypoglycemia, moderate intensity exercise during fasting is suggested. Rather than training in the morning, training in the evening is associated with an enhanced aerobic performance during fasting (58). As the activity of fat-burning enzymes is increased with fasting, athletes may wish to train in the fasting state in the pre-season. However, fasting may cause deterioration of performance in some events; therefore, regulation of the training schedule may minimize such effects (56-61). It is important to be careful about some rules during exercises in the Ramadan (56-61):

- Fasting should not be used as an obstacle for not performing exercises.

- Adding daytime naps into the schedule during fasting can help rest the body.

- In such conditions, body weight loss or mood changes in athletes should be monitored closely.

- Since the most significant anxiety occurs in the early part of Ramadan, appropriate coping strategies should be gradually applied at least two weeks prior to Ramadan.

- If the training or competition is scheduled late in the day, to preserve glycogen stores and to limit sweat losses, athletes should restrict their physical activity before the training or competition.

- Individual monitoring of each fasting athlete can minimize the risk of illness and injury.

Recommendations of exercise for untrained and trained subjects during Ramadan fasting are shown in Table 1 (56-61).

\section{Fasting and CV drug therapy}

Fasting is the behavior of restricting or abstaining from food intake or intake of particular foods and has been part of religious rituals such as Ramadan. During fasting an individual must also refrain from consuming oral medicines and using intravenous fluids. Fasting periods change drug pharmacokinetics which may result in altered pharmacodynamic effects, treatment failure, and increased risk of adverse drug reactions (62). Furthermore, two meals daily are eaten within a short overnight span during Ramadan, particularly in summer. The first meal might be taken immediately after sunset and the second one around five to six hours later. So, adjustments of drug intake according to the Ramadan rhythm is not easy and interferes with medication adherence and compliance (63).

The journey of particular drug in the human body can be summarized in four basic steps: absorption, distribution, metabolism, and excretion (62). Along with the administered dose, these steps determine plasma drug concentrations. Maintaining the plasma drug concentration in the therapeutic window is an essential requirement for drug safety and also effectiveness (62). has a major role in these processes and affects the bioavailability of drugs. Fasting also affects drug metabolisms by modulating the activity of drug metabolizing enzymes involved 


\begin{tabular}{|ll|}
\hline \multicolumn{2}{|l|}{ Table 2. Risk Stratification for fasting during Ramadan based on the underlying disease and symptomatic status } \\
\hline Low risk & High risk \\
\hline Controlled hypertension & Recent myocardial infarction \\
Stable angina pectoris & Recent percutaneous coronary intervention \\
Heart failure (patient with no recent decompensation) & Heart failure (Class IV) \\
Mild-Moderate valvular diseases & Heart failure patients hospitalized for decompensation within 6 months \\
Mild-Moderate Pulmonary Hypertension & Severe pulmonary hypertension \\
Atrial fibrillation & Severe valvular diseases \\
Supraventricular tachycardia & Brugada syndrome \\
& Long QT syndrome \\
& Hypertrophic obstructive cardiomyopathy \\
& Uncontrolled ventricular arrhythmia \\
& Uncontrolled hypertension \\
\hline
\end{tabular}

(62). Drug intake according to the summary of product characteristics is vital for maintaining steady state plasma levels within the therapeutic range. So, changing the time intervals between doses may result in fluctuations of the plasma levels, particularly for drugs that are given in multiple doses. Previous studies have revealed that a majority of patients change the intake pattern of their drugs during Ramadan (63).

Islamic scholars have recently reached a consensus regarding the acceptable usage of both oral and parenteral therapeutics during fasting in Ramadan (64). These drugs include eye and ear drops, vaginal pessaries and washes, injections through the skin, muscle, joints or veins (excluding intravenous nutrition), oxygen and anesthetic gases, sublingual nitrate tablets, mouthwashes, gargle or oral sprays provided nothing is swallowed, and substances absorbed through the skin.

Cardiovascular drug therapy covers a wide spectrum of medications and some of them have a narrow therapeutic window such as warfarin. Besides alterations of cardiovascular drug pharmacokinetics and pharmacodynamics due to the fasting state, changing the timing of a twice-a-day regimen to fit with the start and end of fasting can affect bioavailability, with risks to effectiveness and adverse reactions, especially for drugs with a narrow therapeutic window (63). Although studies on antihypertensive agents have shown no difference in safety and effectiveness during Ramadan fasting when administration times have changed, the data about other cardiovascular therapeutic areas are scarce (39). A recent consensus document prepared by the British Islamic Medical Association (BIMA) has summarized important points about cardiovascular medication usage during Ramadan fasting (48).

Briefly, some recommendations about cardiac medication usage during Ramadan can be summarized as follows;

- Diuretics (Loop and thiazide diuretics, aldosterone antagonists) can augment dehydration during fasting, which may increase adverse drug reactions such as acute kidney injury and electrolyte imbalances. However, withdrawal may cause worsening HF or uncontrolled hypertension. Dose reduction may be considered in patients with HF after careful evaluation by a cardiologist. Taking at suhoor should be considered due to the risk of disturbed sleep from nocturia. Close monitoring of kidney functions and electrolyte levels should be considered, particularly for patients who are taking higher maintenance doses and/or have elevated baseline creatinine levels. Elevated risk should not be overlooked in the summer session due to the longer fasting time and increased risk of dehydration.

- Angiotensin Converting Enzyme inhibitors, Angiotensin II Receptor Blockers, and Neprilysin inhibitors can augment dehydration during fasting, which may increase adverse drug reactions such as orthostatic hypotension, electrolyte imbalances, and acute kidney injury. Withdrawal may cause worsening of HF or uncontrolled hypertension. Close monitoring of kidney functions and electrolyte levels should be considered, particularly in patients who are taking higher maintenance doses and/or have elevated baseline creatinine levels. Elevated risk should not be overlooked in the summer session due to the longer fasting time and increased risk of dehydration. Taking medicines after iftar should be considered. Taking medicines immediately after large meals may cause hypotension and orthostatic symptoms.

- Dehydration during fasting may increase adverse drug reactions of Beta Blockers (i.e. orthostatic hypotension). However, withdrawal may cause worsening angina, HF, cardiac arrhythmias, and uncontrolled hypertension. Taking medicines after iftar should be considered to avoid dizzy spells. Taking medicines immediately after large meals may cause hypotension and orthostatic symptoms. Splitting the daily dose should be considered.

- Dehydration during fasting may increase adverse drug reactions of Calcium Channel Blockers (i.e. orthostatic hypotension). Withdrawal may cause worsening angina and uncontrolled hypertension. Taking medicines after iftar should be considered to avoid dizzy spells. Taking medicines immediately after large meals may cause hypotension and orthostatic symptoms.

- Dehydration associated worsening kidney functions and 
electrolyte imbalances may cause Digitalis toxicity. Digoxin can be taken anytime. Close monitoring of kidney functions and electrolyte levels should be considered.

- Warfarin has many drug and food interactions. Fasting influences the pharmacodynamic effects of warfarin (may lower the time in therapeutic window levels) (65). Warfarin can be taken anytime. Close monitoring of INR values should be considered. In order to keep the INR level constant in patients using coumadin, it is recommended not to change the amount of green vegetables consumed during Ramadan.

- Direct Oral Anticoagulants (DOACs) and posology have some important considerations. If taken early in suhoor and then late in iftar, there may be an un-anticoagulated period in patients who are taking apixaban and dabigatran. It is important to note that withdrawal may cause stroke and systemic embolism. Once daily DOACs may be considered. Due to increased bioavailability, rivaroxaban should be taken after iftar.

- If taken early in suhoor and then late in iftar, there may be a loss of pharmacodynamic effect in patients who are taking ticagrelor. Withdrawal may cause thromboembolic complications such as acute coronary syndrome, stent thrombosis, and stroke. So, once daily antiplatelet agents may be considered.

- Sodium-glucose co-transporter 2 inhibitors (SGLT2i) have small increased risk of ketoacidosis, dehydration and postural hypotension that may be augmented with fasting (66). On the other hand, withdrawal may potentially cause worsening $\mathrm{HF}$.

\section{Conclusions}

Based on the abovementioned data, we have classified the patients as low and high risk according to their diseases and symptom status (Table 2). Patients with high risk are advised not to fast during Ramadan. Patients with low risk can fast during Ramadan but their eligibility for fasting should be assessed individually. Pre-Ramadan clinical assessment is an essential component of management of patients with CVD. This should be focused on the assessment of multiple factors including age, fragility, functional capacity, symptoms, lifestyle, medications, and other concomitant diseases such as diabetes or CKD. The potential risks and benefits of fasting should be discussed with the patient and the final decision to fast or not should be clarified individually with a patient-centered approach. It is also important to follow up low-risk patients who are determined to fast during Ramadan. Physicians may recommend a break in any clinical situation change.

Acknowledgment: The authors would like to thank Ibrahim Halil Inanç, MD for his valuable contribution to this consensus report.

Conflict of interest: None declared.

Peer-review: Externally and internally peer-reviewed.
Authorship contributions: Concept - A.T.A.; Design - A.T.A.; Supervision - A.T.A., M.B.Y.; Data collection \&/or processing - A.T.A., M.K.A., K.S.Ö., I.T., U.Ö.T., M.Y., M.B.Y.; Analysis \&/or interpretation A.T.A., M.K.A., K.S.Ö., I.T., U.Ö.T., M.Y., M.B.Y.; Literature search - A.T.A., M.K.A., K.S.Ö., I.T., U.Ö.T., M.Y., M.B.Y.; Critical review - M.K., E.G., A.Y.

\section{References}

1. Abaïdia $A E$, Daab W, Bouzid MA. Effects of Ramadan Fasting on Physical Performance: A Systematic Review with Meta-analysis. Sports Med 2020; 50: 1009-26. [Crossref]

2. Nugraha B, Ghashang SK, Hamdan I, Gutenbrunner C. Effect of Ramadan fasting on fatigue, mood, sleepiness, and health-related quality of life of healthy young men in summer time in Germany: A prospective controlled study. Appetite 2017; 111: 38-45. [Crossref]

3. Iliaz S, Tural Onur S, Uysal MA, Chousein EGU, Tanriverdi E, Bagci BA, et al. The Adverse Effects and Treatment Results of Smoking Cessation Pharmacotherapy During Fasting/Non-Fasting State. Subst Use Misuse 2017; 52: 969-73. [Crossref]

4. Beltaief K, Bouida W, Trabelsi I, Baccouche H, Sassi M, Dridi Z, et al. Metabolic effects of Ramadan fasting in patients at high risk of cardiovascular diseases. Int J Gen Med 2019; 12: 247-54. [Crossref]

5. Trepanowski JF, Bloomer RJ. The impact of religious fasting on human health. Nutr J 2010; 9: 57. [Crossref]

6. Online. URL; https://www.ncbi.nlm.nih.gov/pubmed/?term=ramadan +fasting

7. Ibrahim M, Davies MJ, Ahmad E, Annabi FA, Eckel RH, Ba-Essa EM, et al. Recommendations for management of diabetes during Ramadan: update 2020, applying the principles of the ADA/EASD consensus. BMJ Open Diabetes Res Care 2020; 8: e001248. [Crossref]

8. Grajower MM, Horne BD. Clinical Management of Intermittent Fasting in Patients with Diabetes Mellitus. Nutrients 2019; 11: 873. [Crossref]

9. Nikfarjam M, Noormohammadi MR, Mardanpour-Shahrekordi E. The effect of fasting on emotional intelligence. National Journal of Laboratory Medicine 2015; 4: 67-71.

10. Mohammadi MR, Larijani B, Sanjari M, Jalili RB. Effects of Ramadan of anxiety and depression. Iran J Endocrinol Metabolism Book of the congress on Health and Ramadan. Endocrine and metabolism research center. Tehran University of Medical Sciences, Tehran, Iran 2001; 27.

11. Moshiri Z. Effect of Ramadan on depression in students of Islamic Azad University, Mahabad. Iran J Endocrinol Metabolism Book of the congress on Health and Ramadan. Endocrine and metabolism research center. Tehran University of Medical Sciences, Tehran, Iran 2001; 49.

12. Dewanti L, Watanabe C, Sulistiawati, Ohtsuka R. Unexpected changes in blood pressure and hematological parameters among fasting and nonfasting workers during Ramadan in Indonesia. Eur $\mathrm{J}$ Clin Nutr 2006; 60: 877-81. [Crossref]

13. Malinowski B, Zalewska K, Węsierska A, Sokołowska MM, Socha $\mathrm{M}$, Liczner $\mathrm{G}$, et al. Intermittent Fasting in Cardiovascular DisordersAn Overview. Nutrients 2019; 11: 673. [Crossref]

14. Alkandari JR, Maughan RJ, Roky R, Aziz AR, Karli U. The implications of Ramadan fasting for human health and well-being. $J$ Sports Sci 2012; 30 Suppl 1: S9-19. [Crossref]

15. de Cabo R, Mattson MP. Effects of Intermittent Fasting on Health, Aging, and Disease. N Engl J Med 2019; 381: 2541-51. [Crossref]

16. Sutton EF, Beyl R, Early KS, Cefalu WT, Ravussin E, Peterson CM. Early Time-Restricted Feeding Improves Insulin Sensitivity, Blood Pressure, and Oxidative Stress Even without Weight Loss in Men with Prediabetes. Cell Metab 2018; 27: 1212-21. [Crossref] 
17. Nematy M, Alinezhad-Namaghi M, Rashed MM, Mozhdehifard M, Sajjadi SS, Akhlaghi S, et al. Effects of Ramadan fasting on cardiovascular risk factors: a prospective observational study. Nutr $\mathrm{J}$ 2012; 11: 69. [Crossref]

18. Dong TA, Sandesara PB, Dhindsa DS, Mehta A, Arneson LC, Dollar $A L$, et al. Intermittent Fasting: A Heart Healthy Dietary Pattern? Am J Med 2020; 133: 901-7. [Crossref]

19. Salim I, AI Suwaidi J, Ghadban W, Alkilani H, Salam AM. Impact of religious Ramadan fasting on cardiovascular disease: a systematic review of the literature. Curr Med Res Opin 2013; 29: 343-54. [Crossref]

20. NasrAllah MM, Osman NA. Fasting during the month of Ramadan among patients with chronic kidney disease: renal and cardiovascular outcomes. Clin Kidney J 2014; 7: 348-53. [Crossref]

21. Horne BD, Muhlestein JB, May HT, Carlquist JF, Lappé DL, Bair TL, et al.; Intermountain Heart Collaborative Study Group. Relation of routine, periodic fasting to risk of diabetes mellitus, and coronary artery disease in patients undergoing coronary angiography. Am J Cardiol 2012; 109: 1558-62. [Crossref]

22. Temizhan A, Dönderici O, Ouz D, Demirbas B. Is there any effect of Ramadan fasting on acute coronary heart disease events? Int J Cardiol 1999; 70: 149-53. [Crossref]

23. Burazeri G, Goda A, Kark JD. Religious observance and acute coronary syndrome in predominantly Muslim Albania: a population-based case-control study in Tirana. Ann Epidemiol 2008; 18: 937-45. [Crossref]

24. Salam AM, Sulaiman $K$, Alsheikh-Ali AA, Singh $R$, Asaad N, Al-Qahtani $A$, et al. Acute heart failure presentations and outcomes during the fasting month of Ramadan: an observational report from seven Middle Eastern countries. Curr Med Res Opin 2018; 34: 237-45. [Crossref]

25. Chamsi-Pasha $\mathrm{H}$, Ahmed WH. The effect of fasting in Ramadan on patients with heart disease. Saudi Med J 2004; 25: 47-51.

26. Amin OA, Alaarag A. The safety of Ramadan Fasting following Percutaneous Coronary Intervention. BMC Cardiovasc Disord 2020; 20: 489. [Crossref]

27. Deutch MR, Grimm D, Wehland M, Infanger M, Krüger M. Bioactive Candy: Effects of Licorice on the Cardiovascular System. Foods 2019; 8: 495. [Crossref]

28. Lai YF, Cheen MH, Lim SH, Yeo FH, Nah SC, Kong MC, et al. The effects of fasting in Muslim patients taking warfarin. $J$ Thromb Haemost 2014; 12: 349-54. [Crossref]

29. Karimi R, Cleven A, Elbarbry F, Hoang H. The Impact of Fasting on Major Metabolic Pathways of Macronutrients and Pharmacokinetics Steps of Drugs. Eur J Drug Metab Pharmacokinet 2021; 46: 25-39. [Crossref]

30. Horton JL, Davidson MT, Kurishima C, Vega RB, Powers JC, Matsuura TR, et al. The failing heart utilizes 3-hydroxybutyrate as a metabolic stress defense. JCI Insight 2019; 4: e124079 [Crossref].

31. Çavuşoğlu Y, Altay H, Cahn A, Celik A, Demir S, Kılıçaslan B, et al. Sodium glucose co-transporter 2 inhibitors in heart failure therapy. Turk Kardiyol Dern Ars 2020; 48: 330-54. [Crossref]

32. Aubert G, Martin OJ, Horton JL, Lai L, Vega RB, Leone TC, et al. The Failing Heart Relies on Ketone Bodies as a Fuel. Circulation 2016; 133: 698-705. [Crossref]

33. Nasser S, Vialichka V, Biesiekierska M, Balcerczyk A, Pirola L. Effects of ketogenic diet and ketone bodies on the cardiovascular system: Concentration matters. World J Diabetes 2020; 11: 584-95. [Crossref]

34. Al Suwaidi J, Bener A, Hajar HA, Numan MT. Does hospitalization for congestive heart failure occur more frequently in Ramadan: a population-based study (1991-2001). Int J Cardiol 2004; 96: 217-21. [Crossref]

35. Hassan S, Hassan F, Abbas N, Hassan K, Khatib N, Edgim R, et al. Does Ramadan Fasting Affect Hydration Status and Kidney Function in CKD Patients? Ann Nutr Metab 2018; 72: 241-7. [Crossref]

36. Abazid RM, Khalaf HH, Sakr HI, Altorbak NA, Alenzi HS, Awad ZM, et al. Effects of Ramadan fasting on the symptoms of chronic heart failure. Saudi Med J 2018; 39: 395-400. [Crossref]

37. Nielsen R, Møller N, Gormsen LC, Tolbod LP, Hansson NH, Sorensen $\mathrm{J}$, et al. Cardiovascular Effects of Treatment With the Ketone Body 3-Hydroxybutyrate in Chronic Heart Failure Patients. Circulation 2019; 139: 2129-41. [Crossref]

38. Chamsi-Pasha H, Ahmed WH, Al-Shaibi KF. The cardiac patient during Ramadan and Hajj. J Saudi Heart Assoc 2014; 26: 212-5. [Crossref]

39. Perk G, Ghanem J, Aamar S, Ben-Ishay D, Bursztyn M. The effect of the fast of Ramadan on ambulatory blood pressure in treated hypertensives. J Hum Hypertens 2001; 15: 723-5. [Crossref]

40. Ural E, Kozdag G, Kilic T, Ural D, Sahin T, Celebi O, et al. The effect of Ramadan fasting on ambulatory blood pressure in hypertensive patients using combination drug therapy. J Hum Hypertens 2008; 22: 208-10. [Crossref]

41. Erdem Y, Özkan G, Ulusoy Ş, Arıcı M, Derici Ü, Şengül Ş, et al.; Turkish Society of Hypertension and Renal Diseases. The effect of intermittent fasting on blood pressure variability in patients with newly diagnosed hypertension or prehypertension. J Am Soc Hypertens 2018; 12: 42-9. [Crossref]

42. Chamsi-Pasha $M$, Chamsi-Pasha $H$. The cardiac patient in Ramadan. Avicenna J Med 2016; 6: 33-8. [Crossref]

43. Topacoglu H, Karcioglu O, Yuruktumen A, Kiran S, Cimrin AH, Ozucelik DN, et al. Impact of Ramadan on demographics and frequencies of disease-related visits in the emergency department. Int J Clin Pract 2005; 59: 900-5. [Crossref]

44. Mzoughi K, Zairi I, Jabeur M, Kraiem S. The effects of fasting on heart rate variability in hypertensive patients. Clin Exp Hypertens 2018; 40: 793-6. [Crossref]

45. Cansel $\mathrm{M}$, Taşolar $\mathrm{H}$, Yağmur J, Ermiş N, Açıkgöz N, Eyyüpkoca F, et al. The effects of Ramadan fasting on heart rate variability in healthy individuals: a prospective study. Anatol J Cardiol 2014; 14: 413-6. [Crossref]

46. Reno CM, Skinner A, Bayles J, Chen YS, Daphna-Iken D, Fisher SJ. Severe hypoglycemia-induced sudden death is mediated by both cardiac arrhythmias and seizures. Am J Physiol Endocrinol Metab 2018; 315: E240-9. [Crossref]

47. Salam AM, AIBinali HA, Salim I, Singh R, Asaad N, Al-Qahtani A, et al. Impact of religious fasting on the burden of atrial fibrillation: a population-based study. Int J Cardiol 2013; 168: 3042-3. [Crossref]

48. Ramadan Rapid Review \& Recommendations. v1 20 April 2020. British Islamic Medical Association. URL; https://britishima.org/ ramadan-rapid-review/

49. Nishizaki M, Sakurada H, Mizusawa Y, Niki S, Hayashi T, Tanaka Y, et al. Influence of meals on variations of ST segment elevation in patients with Brugada syndrome. J Cardiovasc Electrophysiol 2008; 19: 62-8.

50. Nogami A, Nakao M, Kubota S, Sugiyasu A, Doi H, Yokoyama K, et al. Enhancement of J-ST-segment elevation by the glucose and insulin test in Brugada syndrome. Pacing Clin Electrophysiol 2003; 26: 332-7. [Crossref]

51. Ikeda T, Abe A, Yusu S, Nakamura K, Ishiguro H, Mera H, et al. The full stomach test as a novel diagnostic technique for identifying 
patients at risk of Brugada syndrome. J Cardiovasc Electrophysiol 2006; 17: 602-7. [Crossref]

52. Talib S, van de Poll SW. Brugada syndrome diagnosed after Ramadan. Lancet 2013; 382: 100. [Crossref]

53. Hyltén-Cavallius L, lepsen EW, Wewer Albrechtsen NJ, Svendstrup $M$, Lubberding $A F$, Hartmann $B$, et al. Patients With Long-OT Syndrome Caused by Impaired hERG-Encoded Kv11.1 Potassium Channel Have Exaggerated Endocrine Pancreatic and Incretin Function Associated With Reactive Hypoglycemia. Circulation 2017; 135: 1705-19. [Crossref]

54. Kahraman S, Dogan A. Ventricular arrhythmia linked to long intermittent fasting. J Electrocardiol 2020; 58: 125-7. [Crossref]

55. Authors/Task Force members, Elliott PM, Anastasakis A, Borger MA, Borggrefe M, Cecchi F, et al. 2014 ESC Guidelines on diagnosis and management of hypertrophic cardiomyopathy: the Task Force for the Diagnosis and Management of Hypertrophic Cardiomyopathy of the European Society of Cardiology (ESC). Eur Heart J 2014; 35 : 2733-79. [Crossref]

56. Donnelly JE, Blair SN, Jakicic JM, Manore MM, Rankin JW, Smith BK; American College of Sports Medicine Position Stand. Appropriate physical activity intervention strategies for weight loss and prevention of weight regain for adults. Med Sci Sports Exerc 2009; 41: 459-71. [Crossref]

57. Sporcularda ani kalp ölümü. Spora devam eden ve/veya başlamak isteyenlere kılavuz. Editor: Yıldız M. ISBN: 978-605-335-591-5. Nobel Tıp Kitabevleri, İstanbul 2021; S1-141. [Turkish]
58. Vieira AF, Costa RR, Macedo RC, Coconcelli L, Kruel LF. Effects of aerobic exercise performed in fasted $v$. fed state on fat and carbohydrate metabolism in adults: a systematic review and meta-analysis. Br J Nutr 2016; 116: 1153-64. [Crossref]

59. Zouhal H, Saeidi A, Salhi A, Li H, Essop MF, Laher I, et al. Exercise Training and Fasting: Current Insights. Open Access J Sports Med 2020; 11: 1-28. [Crossref]

60. The State of Oatar National Physical Activity Guidelines 2014 First Edition. Ed: Al-Bibi KW. p 54-6.

61. Maughan RJ, Zerguini Y, Chalabi H, Dvorak J. Achieving optimum sports performance during Ramadan: some practical recommendations. J Sports Sci 2012; 30 Suppl 1: S109-17. [Crossref]

62. Lammers LA, Achterbergh R, Mathôt RAA, Romijn JA. The effects of fasting on drug metabolism. Expert Opin Drug Metab Toxicol 2020; 16: 79-85. [Crossref]

63. Aadil N, Houti IE, Moussamih S. Drug intake during Ramadan. BMJ 2004; 329: 778-82. [Crossref]

64. Gilani A. Medicine's management during Ramadan. The Pharmaceutical Journal 2011; 287: 93-4.

65. Sridharan K, Al Banna R, Oader AM, Husain A. Does fasting during Ramadan influence the therapeutic effect of warfarin? J Clin Pharm Ther 2021; 46: 86-92. [Crossref]

66. Hassanein M, Bashier A, Randeree H, Abouelmagd M, AlBaker W, Afandi B, et al. Use of SGLT2 inhibitors during Ramadan: An expert panel statement. Diabetes Res Clin Pract 2020; 169: 108465. [Crossref] 